\title{
Hilar strictures - Clear management strategies start to emerge
}

\author{
Robert Enns MD
}

$\mathrm{T}_{\mathrm{c}}^{\mathrm{h}}$ he management of hilar strictures has continued to be a challenge for endoscopists. There is little consensus in the literature and a host of other variables to consider regarding investigations and management that often serve to add confusion rather than resolution to the issue. A number of different management strategies have been instituted but none of them have had stellar results. This disease, like many palliative situations in gastroenterology, is fraught with difficulty, often ending in the ungratifying end point of death within weeks of a successful procedure.

With an overall five-year survival of $10 \%$ and a median of four to six months, perhaps the first and most important item to consider when managing these patients are the patients themselves. It must be recognized that most of them are palliative. A multidisciplinary team with an understanding in this area is critical in maintaining appropriate patient satisfaction. Although the endoscopist is focused on the resolution of jaundice, improvement of biliary flow and avoidance of cholangitis, these issues may well be secondary to the patient (and the family) who is simply struggling to accept their own mortality. Although endoscopic management of these lesions is the endoscopist's major interest, open communication and involvement of experts in palliation may be more important to the patient than which method decreases the cholangitis rate by $10 \%$.

The issues regarding hilar strictures revolve around the inability to easily access and drain the biliary tree. Because the survival rate is so low, the primary modality of therapy should be endoscopic drainage. Percutaneous drainage, although demonstrated to be successful (1-4), tends to be more painful and often requires hospital admission, which can be avoided if the initial endoscopic therapy is successful. The drainage of a single side of the biliary tree is technically easier but may not result in adequate resolution of jaundice and, additionally, may increase the risk of cholangitis (particularly if injected contrast remains poorly drained in the opposing side). The placement of bilateral stents can be technically difficult but results in improved flow and less cholangitis. However, this offers no survival benefit and may require more endoscopic procedures.

These issues have been studied in a variety of countries with variable and sometimes conflicting results. Initial studies in 1993 randomly assigned hilar patients to metal or plastic stents; there was no difference in morbidity and mortality seen between the two groups. However, there appeared to be a cost-benefit from fewer endoscopic interventions in the metal stent group (5). Clearly, from a patient perspective this has distinct advantages. Although there are limited studies comparing metal versus plastic stents in the setting of hilar lesions, several randomized studies in distal biliary strictures have concluded convincingly that metal stents remain patent longer in the biliary tree (6-11).

In the region of the hilum the data are much less clear. There are at least three key issues to consider. The first is whether magnetic resonance cholangiopancreatography (MRCP) is performed before endoscopic retrograde cholangiopancreatography (ERCP) in an effort to direct the endoscopic effort. In a feasibility study of 35 patients assessed with MRCP (used to guide unilateral endoscopic drainage), a cholangitis rate of $6 \%$ was much lower than many other endoscopic studies (12). Additionally, a potential cost-benefit of MRCP before ERCP has been suggested Robert Enns

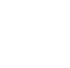


rate of complications ( $27 \%$ versus $19 \%, \mathrm{P}=0.026$ ) without a change in median survival (18). Previous studies have demonstrated that there does not appear to be a major difference between which lobe is drained (even though the lobes are significantly different in size) as long as adequate drainage of one side was accomplished (19). On the other hand, in a retrospective study, Chang et al (20) have suggested that those patients with unilateral drainage with contrast injected bilaterally have a poor outcome. One approach has been to perform an early MRCP to delineate the anatomy and then limit contrast injection, with subsequent stenting to be unilaterally directed by the MRCP as opposed to contrast injection.

The third issue is whether metal or plastic stents be used for management. Several studies have evaluated this question with somewhat conflicting results. In a retrospective study performed over a 10-year period, Cheng et al (21) found that using 52 expandable metal stents in 36 patients resulted in $97 \%$ endoscopic success and only 14\% early complication rate. A single centre prospective study by De Palma et al (22) also demonstrated a $97 \%$ endoscopic success with a single expandable metal stent when placed to the technically, easiest side of the bile duct to access. There was an $86 \%$ resolution of jaundice but late stent occlusion was common (23\%). With the plan outlined above, using MRCP to guide stent placement, Freeman and Overby (14) previously published on 35 patients treated with a single metallic stent with resolution of jaundice in $77 \%$ and no additional intervention required in over $70 \%$ of patients. In the only randomized study comparing plastic with metal stents (in hilar lesions) of 20 patients there appeared to be a benefit of metal in regard to decreased reintervention as well as hospitalizations required for management (5). In this study, technical success was achieved in $100 \%$ of metal stents and $88.9 \%$ of plastic stents. However, percutaneous involvement was often used in addition to endoscopic treatment. Shortterm results demonstrated two malfunctions of the $14 \mathrm{~F}$ plastic stents (by 30 days) and no metal stent dysfunction. Overall, there appeared to be a benefit of metal stents with regard to patency, limiting reintervention and decreased infectious episodes.

With this information as a background, a study by Perdue et al (unpublished data) had been conducted through a multicentre group which prospectively evaluated the outcomes of hilar patients with regard to plastic versus metal stent insertion. Although the study lacked the strength of a prospective, randomized study, the authors are to be applauded on a strong attempt to evaluate their results and in attempting to determine which method results in the best outcomes. There were 62 patients evaluated (34 in the metal stent group) with the groups appearing to be demographically similar. The end point of 30 days was used in the study and was appropriate because the two key issues included early infection and failure of jaundice to

\section{REFERENCES}

1. Eschelman DJ, Shapiro MJ, Bonn J, et al. Malignant biliary duct obstruction: Long-term experience with Gianturco stents and combined-modality radiation therapy. Radiology 1996;200:717-24.

2. Miller DL, Haines GA, Schmetz MA, Ghosh BC.

Percutaneous biliary stents for palliation of hilar malignancies. J Surg Oncol 1996;62:226-7.

3. Roeren T, Tonn W, Richter GM, Brambs HJ, Kauffmann G. Percutaneous therapy of malignant obstructive jaundice using expandable metal stents: A prospective study of 92 patients. Rofo $1996 ; 165: 181-7$. resolve. Additionally, in a retrospective study, it is likely that early data are more accurate and clearly easier to collect. The primary finding in the study was that $40 \%$ of patients who had plastic stents inserted required reintervention within the 30-day window as opposed to only $12 \%$ in the metal group ( $\mathrm{P}=0.017)$. As expected in a 30-day study, there were no differences in mortality. Most impressive in this study are the actual stentrelated complications that occurred, with only $9 \%$ of the metal stent group having direct complications (cholangitis, perforation, migration and occlusion) compared with $32 \%$ in the plastic stent group. Only five patients who received metal stents and four of the plastic group had stents placed bilaterally, thus, most of the group had unilateral stent placement. Because the study was conceived before data on MRCP, many of these patients would not have had their placement guided by a pre-ERCP MRCP. Despite this, the 30-day reintervention rate is relatively low for those patients who received metal stent therapy. One of the explanations for this lies in the expertise of the centres involved. Most of the hilar cases were performed in academic settings where experienced endoscopists optimized the patient's outcomes. In the final analysis to review predictors, plastic stents and bilirubin (in the logistic regression analysis) were determined to be key variables that were associated with adverse outcomes.

Because this study was not randomized and the option to insert each stent was in the control of the endoscopist, some differences between the two groups likely emerged. In the group that received metal stents, patients appeared to have more advanced disease, as demonstrated by a higher Bismuth class. Typically, this type of disease is even more difficult to drain adequately and yet we find that, despite a bias toward more difficult patients, metal stenting was still more successful. Additionally, the Charlson index was higher in the metal stent group, lending support to the hypothesis that the metal stents were likely inserted in patients who may have had more severe disease and were, therefore, unlikely to be surgical candidates.

So what can we take from all of these studies? This study has added more information and strength to the use of metal stents most commonly with unilateral placement. It appears reasonable to consider MRCP before the procedure to confirm the nature of the disease and direct the placement of the stent. Over-injection of contrast without adequate drainage should likely be avoided because it appears to increase the risk of adverse events. Bilateral plastic stent placement is likely not required in most patients and insertion of a single metal stent (in the palliative patient) appears to be adequate for most patients. The evolving nature of this area will continue to develop as new technology (such as photodynamic therapy) continues to be studied (23). It is likely that as these new techniques emerge, the management strategy will continue to be adjusted.

4. Schima W, Prokesch R, Osterreicher C, et al. Biliary Wallstent endoprosthesis in malignant hilar obstruction: Long-term results with regard to the type of obstruction. Clin Radiol 1997;52:213-9.

5. Wagner HJ, Knyrim K, Vakil N, Klose KJ. Plastic endoprostheses versus metal stents in the palliative treatment of malignant hilar biliary obstruction. A prospective and randomized trial. Endoscopy 1993;25:213-8.

6. Carr-Locke DL, Ball TJ, Connors PJ, et al. Multicenter, randomized trial of Wallstent biliary endoprosthesis versus plastic stents. Gastrointest Endosc 1993;39(Suppl A):310A. 
7. Davids PH, Groen AK, Rauws EA, Tytgat GN, Huibregtse K. Randomised trial of self-expanding metal stents versus polyethylene stents for distal malignant biliary obstruction. Lancet 1992;340:1488-92.

8. Huibregtse K, Carr-Locke DL, Cremer M, et al. Biliary stent occlusion - a problem solved with self-expanding metal stents? European Wallstent Study Group. Endoscopy 1992;24:391-4.

9. Knyrim K, Wagner HJ, Pausch J, Vakil N. A prospective, randomized, controlled trial of metal stents for malignant obstruction of the common bile duct. Endoscopy 1993;25:207-12.

10. Lammer J, Hausegger KA, Fluckiger F, et al. Common bile duct obstruction due to malignancy: Treatment with plastic versus metal stents. Radiology 1996;201:167-72.

11. Prat F, Chapat O, Ducot B, et al. A randomized trial of endoscopic drainage methods for inoperable malignant strictures of the common bile duct. Gastrointest Endosc 1998;47:1-7.

12. Hintze RE, Abou-Rebyeh H, Adler A, Veltzke-Schlieker W, Felix R, Wiedenmann B. Magnetic resonance cholangiopancreatography-guided unilateral endoscopic stent placement for Klatskin tumors. Gastrointest Endosc 2001;53:40-6.

13. Harewood GC, Baron TH. Cost analysis of magnetic resonance cholangiography in the management of inoperable hilar biliary obstruction. Am J Gastroenterol 2002;97:1152-8.

14. Freeman ML, Overby C. Selective MRCP and CT-targeted drainage of malignant hilar biliary obstruction with self-expanding metallic stents. Gastrointest Endosc 2003;58:41-9.

15. Lopera JE, Soto JA, Munera F. Malignant hilar and perihilar biliary obstruction: Use of MR cholangiography to define the extent of biliary ductal involvement and plan percutaneous interventions. Radiology 2001;220:90-6.
16. Naiki T, Shiratori Y, Kanematsu M, et al. Potential utility of magnetic resonance cholangiography in the management of endoscopic biliary drainage tubes. Am J Gastroenterol 1999;94:2531-3.

17. Zidi SH, Prat F, Le Guen O, Rondeau Y, Pelletier G. Performance characteristics of magnetic resonance cholangiography in the staging of malignant hilar strictures. Gut 2000;46:103-6.

18. De Palma GD, Galloro G, Siciliano S, Iovino P, Catanzano C. Unilateral versus bilateral endoscopic hepatic duct drainage in patients with malignant hilar biliary obstruction: Results of a prospective, randomized, and controlled study. Gastrointest Endosc 2001;53:547-53

19. Polydorou AA, Chisholm EM, Romanos AA, et al. A comparison of right versus left hepatic endoprosthesis insertion in malignant hilar biliary obstruction. Endoscopy 1989;21:266-71.

20. Chang WH, Kortan P, Haber G. Outcome in patients with bifurcation tumors who undergo unilateral versus bilateral hapatic duct drainage. Gastrointest Endosc 1998;47:354-62.

21. Cheng JL, Bruno MJ, Bergman JJ, Rauws EA, Tytgat GN, Huibregtse K. Endoscopic palliation of patients with biliary obstruction caused by nonresectable hilar cholangiocarcinoma: Efficacy of self-expandable metallic Wallstents. Gastrointest Endosc 2002;56:33-9.

22. De Palma GD, Pezzullo A, Rega M, et al. Unilateral placement of metallic stents for malignant hilar obstruction: A prospective study. Gastrointest Endosc 2003;58:50-3.

23. Ortner MA, Liebetruth J, Schreiber S, et al. Photodynamic therapy of nonresectable cholangiocarcinoma. Gastroenterology $1998 ; 114: 536-42$. 


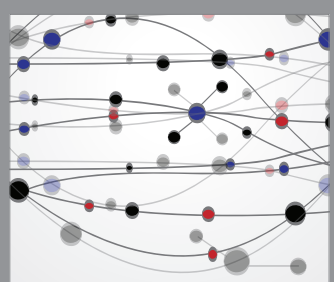

The Scientific World Journal
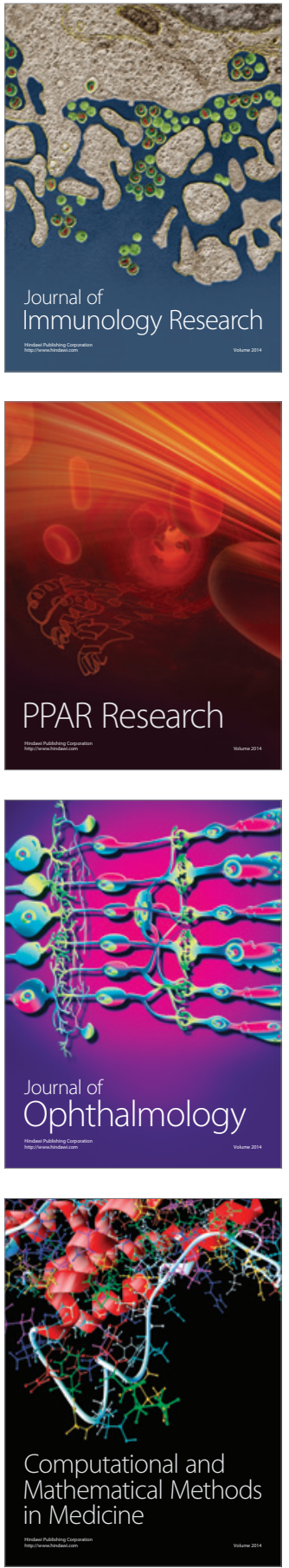

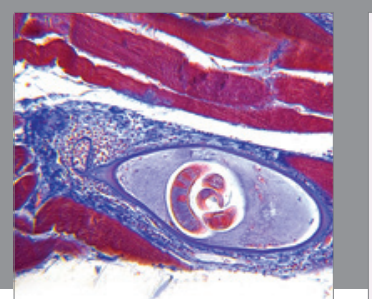

Gastroenterology Research and Practice

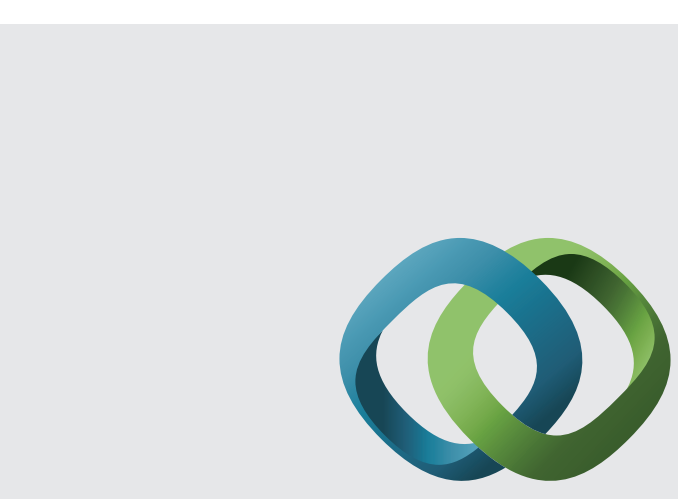

\section{Hindawi}

Submit your manuscripts at

http://www.hindawi.com
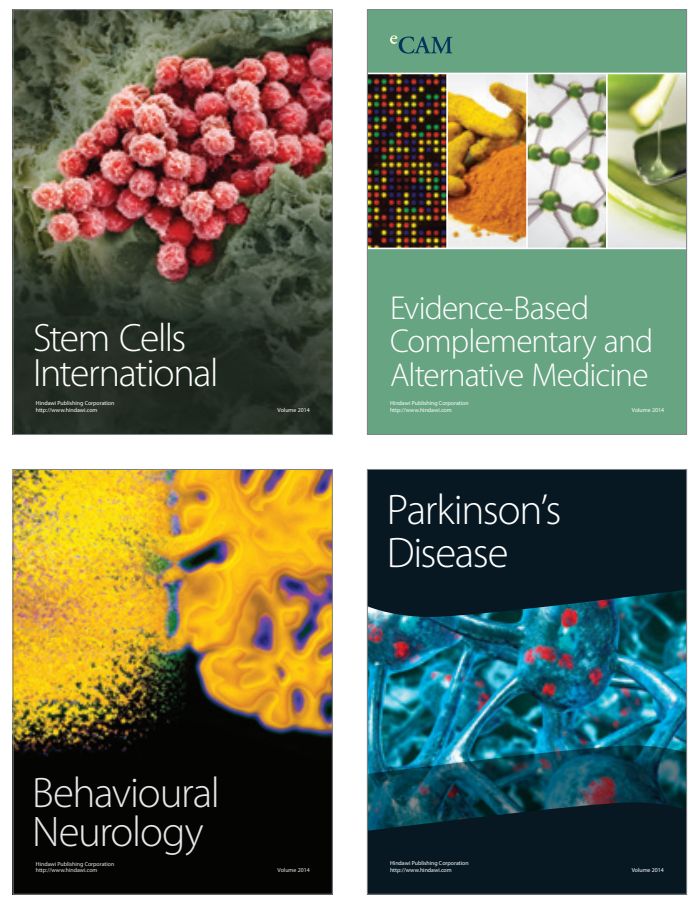
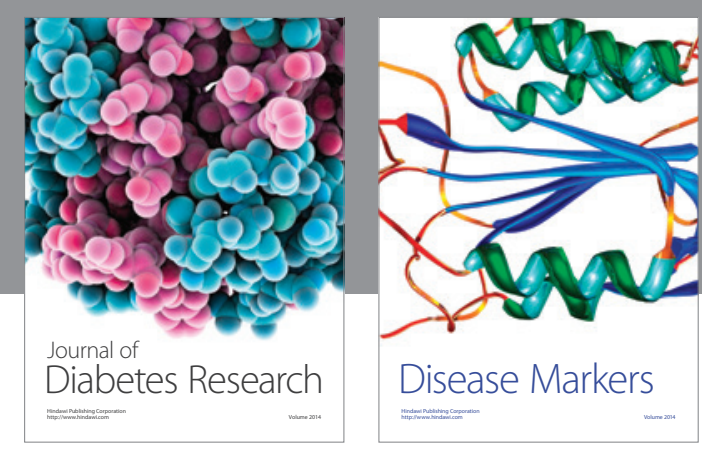

Disease Markers
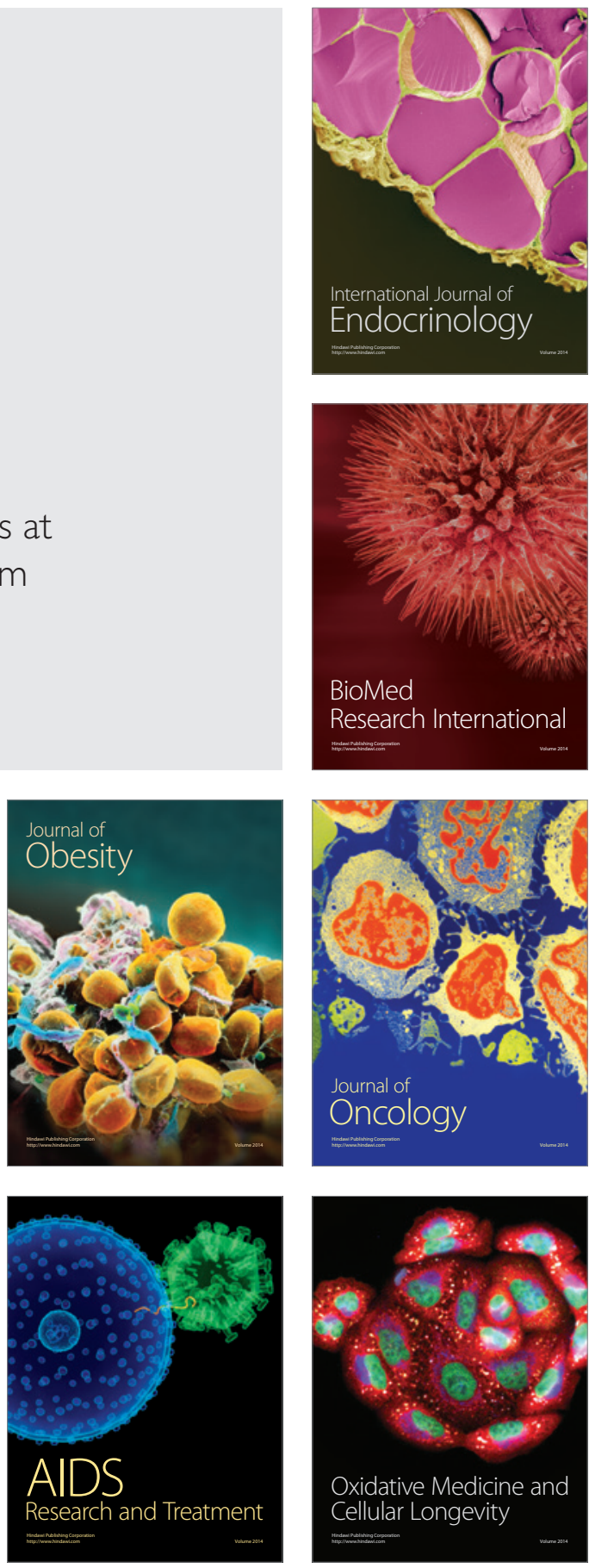